Available online on 15.3.2018 at http://ujpr.org
Universal Journal of Pharmaceutical Research
An International Peer Reviewed Journal
Open access to Pharmaceutical research

\title{
DETERMINING THE IMPACT RATE OF TRIAGE TRAINING ON AWARENESS AND SKILL LEVEL OF PRE-HOSPITAL EMERGENCY PERSONNEL OF FASA CITY

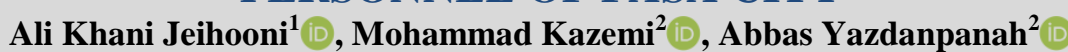 \\ ${ }^{I}$ Department of Public Health. School of Health, Fasa University of Medical Sciences, Fasa, Iran. ${ }^{2}$ Department of Healthcare Management, Marvdasht Branch, Islamic Azad University, Marvdasht, Iran.
}

\section{ABSTRACT}

Objectives: This study was conducted with the aim of determining the impact of triage training on awareness and skill level of prehospital emergency personnel of Fasa City. The present study is applied in respect of objective.

Methods: The statistical population of this study includes all members of crisis management system of Fasa emergency 115 $(n=103)$ that the sample was considered equal to the population. The questionnaire has been adjusted based on 5-value Likert scale. For analysis of data collected from Pearson correlation coefficient, the research hypotheses were examined and tested using SPSS software version 18 .

Results: There is a significant positive relation between participating in training courses and triage awareness of Fasa city prehospital emergency personnel. Also, there is a significant and positive relation between participating in training courses and triage skill of Fasa City pre-hospital emergency personnel.

Conclusion: Study concludes that, with healthcare information, it is recommended that the topics relating to performance and awareness to be noticed by authorities.

Keywords: Awareness level, Fasa, pre-hospital emergency, triage training.

Article Info: Received 16 December 2017; Revised 25 January; Accepted 26 February, Available online 15 March 2018

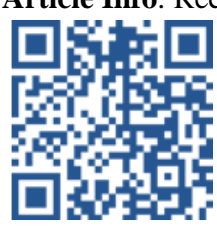
Cite this article-

Jeihooni AK, Kazemi M, Yazdanpanah A. Determining the impact rate of triage training on awareness and skill level of pre-hospital emergency personnel of Fasa city. Universal Journal of Pharmaceutical Research 2018; 3(1): 61-66.

DOI: http://doi.org/10.22270/ujpr.v3i1.R10

Address for Correspondence

Ali Khani Jeihooni, Department of Public Health. School of Health, Fasa University of Medical Sciences, Fasa, Iran. E-mail: khani_1512@yahoo.com.

\section{INTRODUCTION}

Main and primary role of emergency department is to treat severely injured patients ${ }^{1}$. The main prophecy of every emergency department includes providing the most appropriate cares in the shortest possible time ${ }^{2}$. Emergency department s every day faces presence of patients with various problems with varied degrees of severity. Studies show that between $20-60 \%$ of total patients referring to emergency department refer to this department due to urgent, but yet simple and without complication problems that the urgent and effective care of them is possible in lower levels of healthcare centers $^{3}$. The hospital emergency department has a special significance since it receives the greatest, most various, most involved and most sensitive group of patients. According to declaration of World Health Organization, one third of hospital beds have been occupied due to incidents that the first place of hospitalizing such patients is the hospitals emergencies and loss due to it is more than 500 million Dollars ${ }^{4,5}$. Most emergency department $\mathrm{s}$ doesn't have required facilities proportionate to references rate ${ }^{6}$. Crowd in emergency department $\mathrm{s}$ is considerable in all regions of the country as a serious challenge. Sometimes, referees crowd is so that patients wait for more than 60 minutes. This matter is especially significant when cares are provided with delay since influences patients satisfaction rate. Here the triage as the first point of meeting of the hospital emergency team with the patient and his relatives will undertake a unique role in realizing the department final prophecy ${ }^{8}$. Triage in emergency department the quick process of dividing patients referring to emergency so that patients who need more care. In fact, triage is determining correct patient, utilizing correct resources in correct place and time. Triage is the beginning of clinical stages of caring patients and triage and its results analysis indicates performance and status of emergency 
department ${ }^{9}$. Triage should be performed in the hospitals where more than 30000 patients refer to their emergency department each year ${ }^{10}$. Triage in emergency department prioritizes the way of adjusting and scheduling or designating the resources required for the patients and always seeks to provide effective treatment methods for more needful patients and patients with less severity or treatment need generally wait $^{11}$. The results of performance of emergency departments in some countries such as Australia indicates that determining triage in the primary stage is undertaken by professional and skillful nurses (Ton, 2007). Increasing the number of specialized clinical nurses in emergency department minimizes the population crowd and waiting time and leads to patients' satisfaction $^{12}$. Nurses are the greatest and the most important professional group in healthcare system and play a sensible role that should have sufficient skill and attitude in all nursing fields ${ }^{13}$. The required criterion for a nurse (especially in effective triage) is the nursing skill and experience in emergency department especially in fast evaluation and recognition of the patient needs. The ability of these nurses in identifying, interpreting and controlling the patient's physiological abnormalities is very significant. Since is highly effective in reducing mortality and illness symptoms. Nurses progress in emergency domains depends on sufficient levels of clinical training and supports applied in this field. Lack of standard training in triage domain has some destructive consequences $^{14}$. So, for increasing stability in the decision making domain of treatment categories on behalf of medics and paramedics, special traineeship sessions are considered ${ }^{15}$. The main role of triage nurse is to determine the priority of clinical care of patients and should be always considered as the primary aim of patient's triage. They have divided the factors effective in triage nurses decision making in two classes of internal and external factors. Internal factors include nurses' relational skills and their individual features ${ }^{16}$. Nurses skills relates to their experiences, knowledge and direct perception feeling. Also, in triage nurses features, moral courage, doubt feeling, confidence and logic have been pointed out. External factors effective in decision making of triage nurses include working environment status (working pressure imposed on triage nurses) and way of evaluating patients ${ }^{17}$. Regarding dynamicity of triage activities, the best and the most experienced people should be selected for this job. Since triage system setting up in the healthcare centers of the country is young, creating triage culture and training during education and after that for emergency personnel is. So, the present study is conducted with the aim of investigating the impact of triage training on awareness and skill of pre-hospital emergency personnel of Fasa City ${ }^{18}$.

\section{METHODS}

The present study method is descriptive of survey type and the statistical population in the present study includes all members of crisis management system of Fasa 115 emergency. And their number according to the obtained statistics is 103. Regarding Cochran table for the limited society, the sample was considered equal to the society ${ }^{19,20}$. All members were considered. For collecting the considered data for the rate of impact of triage training on the skill and awareness of Fasa city pre-hospital emergency personnel the scholar made questionnaire was used. The questionnaires have been adjusted based on 5-value Likert scale and include 5 ranges ( very low, low, mean, high, very high) which has designated scores 1, 2, 3, 4, 5 respectively from very low to very high. This questionnaire includes 29 questions. The validity indicator of assessment tool items was of nominal validity of expert's consensus and the validity of the questionnaire was confirmed by analyzing exploratory factor and reliability was confirmed using Cronbach's alpha method that reliability factor of 0.83 was obtained for the whole questionnaire. The results have been stated regarding SPSS software and statistics in two levels of descriptive and inferential ${ }^{21}$.

\section{RESULTS}

For using parametric tests in order to investigate the research hypotheses, the normality of variables using Kolmogorov- Smirnov was confirmed (by observing Table 1 and investigating significance of all subscales that are greater than 0.05$)^{22,23}$.

\begin{tabular}{|c|c|c|c|}
\hline $\begin{array}{c}\text { Significance } \\
\text { level }\end{array}$ & Kol & $\begin{array}{l}\text { ogorov- Smirnov } \\
\text { statistics }\end{array}$ & $\begin{array}{c}\text { Variable } \\
\text { name }\end{array}$ \\
\hline 0.112 & 0.423 & Training classes & \multirow{5}{*}{$\begin{array}{l}\text { Triage } \\
\text { training }\end{array}$} \\
\hline 0.142 & 0.510 & $\begin{array}{c}\text { Awareness towards } \\
\text { personnel triage }\end{array}$ & \\
\hline 0.100 & 0.812 & $\begin{array}{c}\text { Skill about } \\
\text { personnel triage }\end{array}$ & \\
\hline 0.178 & 0.761 & Triage training & \\
\hline 0.123 & 0.542 & $\begin{array}{l}\text { Demographic } \\
\text { features }\end{array}$ & \\
\hline
\end{tabular}

As it is observed in Table 2, regarding the correlation factor and significance level $(\mathrm{r}=0.727, p=0.001)$, there is a significance and positive relation between participating in training classes and awareness of triage of Fasa City pre-hospital emergency personnel.

Table 2: The results of Pearson correlation test.

\begin{tabular}{ccc}
\hline $\begin{array}{c}\text { Significance } \\
\text { level } \\
(\mathbf{p})\end{array}$ & $\begin{array}{c}\text { Pearson } \\
\text { Correlation } \\
\text { coefficient } \\
(\mathbf{r})\end{array}$ & $\begin{array}{c}\text { Statistical indicator and } \\
\text { variable }\end{array}$ \\
\hline $0.001 *$ & 0.27 & $\begin{array}{c}\text { Between participating in } \\
\text { training classes and } \\
\text { awareness towards pre- } \\
\text { hospital emergency } \\
\text { personnel triage }\end{array}$ \\
\hline $0.001 *$ & & $\begin{array}{c}\text { Participating in training } \\
\text { classes and awareness } \\
\text { towards pre-hospital } \\
\text { emergency personnel } \\
\text { triage }\end{array}$ \\
\hline
\end{tabular}

Regarding the correlation factor and significance level $(p=0.001, \mathrm{r}=0.696)$, there is a significance and positive relation between training classes and skill towards 
triage of Fasa city pre-hopsital emergency personnel. As it is observed in Table 3, regarding the obtained correlation factor and significance level, there is no significant relation between any of demographic features (age, service record, education rate, sport history, marital status) and awareness towards emergency personnel triage ${ }^{24}$.

Table 3: The results of Pearson correlation analysis between demographic features and awareness towards emergency personnel triage.

\begin{tabular}{ccc}
\hline $\begin{array}{c}\text { Significance } \\
\text { level }\end{array}$ & $\begin{array}{c}\text { Correlation } \\
\text { factor }\end{array}$ & $\begin{array}{c}\text { Individual } \\
\text { features }\end{array}$ \\
\hline 0.231 & 0.032 & Age \\
0.324 & $0.053-$ & Service record \\
0.145 & $0.111-$ & Education rate \\
0.189 & 0.102 & Marital status \\
\hline
\end{tabular}

As it is observed in Table 4, regarding obtained correlation factor rate and significance level, there is no significance relation between any of demographic features (age, service record, education rate, sport history, marital status) with skill towards Fasa City prehospital emergency personnel triage skill.

Table 4: Pearson Correlation analysis results between demographic variables and skill towards pre-hospital emergency personnel triage.

\begin{tabular}{|c|c|c|}
\hline $\begin{array}{c}\text { Significance } \\
\text { level }\end{array}$ & $\begin{array}{c}\text { Correlation } \\
\text { factor }\end{array}$ & $\begin{array}{c}\text { Individual } \\
\text { features }\end{array}$ \\
\hline 0.123 & 0.051 & Age \\
\hline 0.145 & 0.101 & $\begin{array}{l}\text { Service } \\
\text { record }\end{array}$ \\
\hline 0.201 & 0.101 & $\begin{array}{l}\text { Education } \\
\text { rate }\end{array}$ \\
\hline 0.354 & 0.105 & $\begin{array}{c}\text { Marital } \\
\text { status }\end{array}$ \\
\hline
\end{tabular}

Table 5 shows the average impact of triage training on awareness level Fasa city pre-university emergency personnel and their comparison with acceptable adequacy level criteria (Q2) and optimal level (Q3). It is observed that the average of impact of triage training factors (3.61) has been evaluated higher than acceptable adequacy level $(\mathrm{Q} 2=3)$, based on the obtained $t$ rate in freedom degree of 102 , a significance difference has been obtained in level 0.0001 between two averages. The average of triage training impact on awareness level of Fasa City pre-hospital emergency personnel has been observed lower than optimal level $(\mathrm{Q} 3=4)$ and based on the obtained $t$ rate in freedom level 102 a significance difference has been obtained in 0.0001 level between these two averages.
These findings means that the impact rate of triage training on awareness level of Fasa City pre-hospital emergency personnel is higher than acceptable adequacy level but lower than the optimal level ${ }^{25}$. Table 6 shows that average of triage training impact on Fasa City pre-hospital emergency personnel skill level and also its comparison with criteria of acceptable adequacy level (Q2) and optimal level (Q3). It is observed that the average of triage training impact (3.57) has been evaluated higher than acceptable adequacy level $(\mathrm{Q} 2=3)$. Based on the $t$ rate obtained in freedom degree 102, a significance difference in level 0.0001 between two averages has been obtained. The average of triage training impact on Fasa City prehospital emergency personnel skill level has been evaluated lower than optimal level $(\mathrm{Q} 3=4)$ and based on the $\mathrm{t}$ rate obtained in freedom degree 102, a significance difference has been obtained in level 0.0001 between these two averages. These findings mean that the impact rate of triage training on Fasa City pre-hospital emergency personnel skill level is higher than the acceptable level but lower than the optimal level $^{26}$.

\section{DISCUSSION AND CONCLUSION}

The results of the study showed that there is a positive and significant relation between participating in training classes and awareness of Fasa City prehospital emergency towards triage. Therefore, based on significance level of the research hypothesis, the research hypothesis is verified and is consistent with findings of Gonzalez et al., Jalil et al., and Pahlavani et al., Gonzalez et al., in a study, under the title of the relation of triage training and awareness and performance of emergency personnel concluded that triage training increases awareness and performance and trained people has more awareness and performance than non-trained people ${ }^{27,28,29}$. Also, the regression results in this study showed that awareness and performance could predict triage training. Jalil et al., in a study under the title of awareness and performance of Pakistan emergency personnel about pre-hospital triage concluded that training has a positive and significant relation with awareness and performance of Pakistan emergency personnel ${ }^{19}$.

Also, demographic features have a more effective relation with the personnel awareness and performance. Mehr et al., in a study about the relation between triage training and emergency personnel performance and awareness concluded that triage training has a positive and significant relation with performance and awareness of emergency personnel ${ }^{17}$.

Table 5: Comparing the impact rate of triage training on awareness level of Fasa City pre-hospital emergency personnel with acceptable adequacy level (Q2) and optimal level (Q3).

\begin{tabular}{cccccccccc}
\hline Variable & Average & $\begin{array}{c}\text { Standard } \\
\text { deviation }\end{array}$ & $\begin{array}{c}\text { Acceptable } \\
\text { adequacy } \\
\text { level (Q2) }\end{array}$ & t rate & $\begin{array}{c}\text { Freedom } \\
\text { degree }\end{array}$ & $\begin{array}{c}\text { Significance } \\
\text { level }\end{array}$ & $\begin{array}{c}\text { Optimal } \\
\text { level } \\
\text { (Q3) }\end{array}$ & $\begin{array}{c}\text { T rate } \\
\text { Significance } \\
\text { level }\end{array}$ \\
\hline $\begin{array}{c}\text { Triage } \\
\text { training } \\
\text { and }\end{array}$ & 3.61 & 0.83 & 3 & 11.55 & 102 & 0.0001 & 4 & 7.34 & 0.0001 \\
freedom & & & & & & & & & \\
\hline
\end{tabular}


Table 6: Comparison of the impact of triage training on Fasa City pre-hospital emergency personnel skill with acceptable adequacy (Q2) and optimal level (Q3).

\begin{tabular}{ccccccccc}
\hline Variable & average & $\begin{array}{c}\text { Standard } \\
\text { deviation }\end{array}$ & $\begin{array}{c}\text { Acceptable } \\
\text { adequacy } \\
\text { level (Q2) }\end{array}$ & t rate & $\begin{array}{c}\text { Freedom } \\
\text { degree }\end{array}$ & $\begin{array}{c}\text { Significance } \\
\text { level }\end{array}$ & $\begin{array}{c}\text { Optimal } \\
\text { level } \\
\text { (Q3) }\end{array}$ & $\begin{array}{c}\text { T rate } \\
\text { Significance } \\
\text { level }\end{array}$ \\
\hline $\begin{array}{c}\text { Triage } \\
\text { training } \\
\text { and skill } \\
\text { level }\end{array}$ & 3.61 & 0.83 & 3 & 11.55 & 102 & 0.0001 & 4.34 \\
\hline
\end{tabular}

Also, there was a correlation matrix between components of awareness and performance of emergency personnel and triage training. Also, triage training predicts awareness and performance of emergency personnel. There is a significant relation between participating in training classes and skill towards Fasa City pre-hospital emergency personnel triage. The results of the study showed that there is a significant and positive relation between participating in training classes and skill towards Fasa city prehospital emergency personnel triage ${ }^{31}$. Therefore, based on the significance level, the research hypothesis is confirmed and is consistent with findings of Gonzalez et al., Manor et al. and Pahlavani et al., Gonzalez et al., in a study under the title of triage training relation with awareness and performance of emergency personnel concluded that triage training increases awareness and performance and trained people has more awareness and performance than non-trained people $e^{17,32,33}$. Also, the regression results in this study showed that awareness and performance could predict triage training. Jalil et $a l$. , in a study under the title of awareness and performance of Pakistan emergency personnel about pre-hospital triage concluded that training has a positive and significant relation with awareness and performance of Pakistan emergency personnel ${ }^{19}$. Also, demographic features have a more effective relation with the personnel awareness and performance. In a study about the relation between triage training and emergency personnel performance and awareness concluded that triage training has a positive and significant relation with performance and awareness of emergency personnel ${ }^{34}$. Also, there was a correlation matrix between components of awareness and performance of emergency personnel and triage training. Also, triage training predicts awareness and performance of emergency personnel. The results of the study showed that regarding the correlation factor rate and the obtained significance level, there is no relation between any of demographic features (age, service record, education rate, sport history, marital status) and Fasa City pre-hospital emergency personnel awareness of triage. A previous study was performed related to triage training relation with awareness and performance of Gorgan emergency department. The obtained results have shown that there is a positive and moderate correlation factor $(0.363)$ between triage training and performance of emergency department ${ }^{34}$. The obtained significance rate is 0.037 and also the multivariate regression results showed that triage training could be predictor of emergency department performance more than $11 \%$. In a study related to investigating knowledge and performance of emergency department nurses about hospital triage concluded that there is no significant relation between demographic features and knowledge ${ }^{35}$. Also, there is a significant and positive relation between demographic features and their performance. In a study related to the impact of training on awareness and performance of emergency department nurses in the field of patients triage concluded that there was no significant relation between nurses personal features and their score 6 weeks after training, while there was a significant relation between nursing history, working in emergency department, type of employment and average of performance scores in six week after training ${ }^{36}$. Also, no significant relation was found between type of academic degree, marital status and gender of participating people and the average of awareness scores and performance in six weeks after completion of training workshop. And it seems that training has had a positive impact on increasing awareness and performance of nurses in the field of patients' triage. In a study related to investigating the impact of triage training on awareness, attitude and performance of nurses working in emergency department of Rasht City Poorsina training treatment center concluded that the average of triage awareness score has significantly increased from 16.25 before training to 30.75 after training, the average score of triage attitude from 126.75 before training to 154.95 after training and the average score of triage performance from 39.77 before training to 55.85 after training $(P=0.0001)$. Other results showed that there is a significant relation between marital status and people working shift and the average of scores promotion in the awareness domain $(P<0.05)$. Also, findings showed that triage training has been effective on awareness rate, attitude and performance of personnel working in emergency department. The results of the study showed that regarding the correlation factor and significance level obtained, there is no significant relation between demographic features (age, service record, education rate, sport history and marital status) with skill towards Fasa city pre-hospital emergency personnel triage. In a study related to investigating triage training relation with awareness and performance of Gorgan emergency department ${ }^{37}$. The obtained results have shown that there is a positive and moderate correlation factor ( 0.363$)$ between triage training and performance of emergency department. The obtained significance rate is 0.037 and also the multivariate regression results showed that triage training could be predictor of 
emergency department performance more than $11 \%$. In a study under the title of investigating knowledge and performance of emergency department nurses about hospital triage concluded that there is no significant relation between demographic features and knowledge. Also, there is a significant and positive relation between demographic features and their performance. In a study related to the impact of training on awareness and performance of emergency department nurses in the field of patients triage concluded that there was no significant relation between nurses personal features and their score 6 weeks after training, while there was a significant relation between nursing history, working in emergency department, type of employment and average of performance scores in six week after training $^{38}$. In a study related to investigating the impact of triage training on awareness, attitude and performance of nurses working in emergency department of Rasht City Poorsina training treatment center concluded that the average of triage awareness score has significantly increased from 16.25 before training to 30.75 after training, the average score of triage attitude from 126.75 before training to 154.95 after training and the average score of triage performance from 39.77 before training to 55.85 after training $(P=0.0001)^{37}$. Other results showed that there is a significant relation between marital status and people working shift and the average of scores promotion in the awareness domain $(P<0.05)$. Also, findings showed that triage training has been effective on awareness rate, attitude and performance of personnel working in emergency department. There is a significant relation between demographic variables and skill of Fasa City pre-hospital emergency personnel triage. The results of the study showed the rate of triage training impact on personnel awareness is higher than acceptable level but it is lower than the optimal level. In a study under the title of investigating awareness rate and performance of personnel of medical emergency about pre-hospital training concluded that the rate of awareness of studied people of triage was in medium extent. Also, the results of performance section indicate medium performance of employees ${ }^{40}$. In a study under the title of predicting triage training based on performance, intelligence, satisfaction and awareness concluded that triage training has a considerable impact on research variables ${ }^{39}$. Also, the results showed that there is a significant relation with performance. In a study under the title of the impact of triage training on awareness and performance of emergency department in the field of patients triage concluded that awareness, attitude and performance of personnel after 6 weeks have considerably increased. Also, there is a significant relation between demographic features and awareness and performance. Also, no significant relation was observed between demographic features and awareness and performance. Has triage training an impact on Fasa city pre-hospital emergency personnel skill level? The results of the study showed the rate of triage training impact on personnel awareness is higher than acceptable level but it is lower than the optimal level. In a study related to investigating awareness rate and performance of personnel of medical emergency about pre-hospital training concluded that the rate of awareness of studied people of triage was in medium extent. Also, the results of performance section indicate medium performance of employees ${ }^{37}$. He concluded that awareness and performance of pre-hospital emergency personnel of North Khozestan province about pre-hospital triage was in the medium level. In a study under the title of predicting triage training based on performance, intelligence, satisfaction and awareness concluded that triage training has a considerable impact on research variables ${ }^{38}$. Also, the results showed that there is a significant relation with performance. In a study related to training on awareness and performance of emergency department in the field of patients triage concluded that awareness, attitude and performance of personnel after 6 weeks have considerably increased ${ }^{39}$. Also, there is a significant relation between demographic features and awareness and performance. Also, no significant relation was observed between demographic features and awareness and performance $^{40}$.

\section{AUTHOR'S CONTRIBUTION}

The manuscript was carried out, written, and approved in collaboration with all authors.

\section{ACKNOWLEDGEMENTS}

The authors extend their thanks and appreciation to the Fasa University of Medical Sciences, Fasa, Iran to provide necessary facilities for this work.

\section{CONFLICT OF INTEREST}

No conflict of interest associated with this work.

\section{REFERENCES}

1. Ebrahimi $\mathrm{S}$, et al. Improving interactivity and integrity of health information systems with IHE, 2015. https://doi.org/10.1097/PPO.0b013e318225ff89

2. Ekhvat $\mathrm{M}$, et al. Investigating the search behavior of Kerman City health information and the role of public libraries in this field, 2016. https://doi.org/10.5455/aim.2016.24.56-60

3. Farkhondeh A. Moghadasi Hamid. Hosseini, Azamsadat. Dehghani Mohammad. Status of information management of outpatient care in hospitals affiliated to Tehran City Universities of Medical Sciences, health information management 2012; 9, 432-439.

4. Ekhvati, Maryam, et al. Investigating the search behavior of Kerman City health information and the role of public libraries in this field, 2016. https://doi.org/10.5455/aim.2016.24.56-60

5. Bahreinian, Abdolhamid, Saadat, Razieh, Shakeri, Nezhat, Azizi, Fereydoon. Investigating the patient's attitude towards spirituality impact on their treatment trend. Medical moral J 2010; 14, 1314-148. https://doi.org/10.1370/afm.736

6. Family Physician, what you should know about family physician. Ministry of health, treatment and medical training 2012.

7. Mashaallah T, Safdari R. Health electronic record, Behineh Publications, 2004.

8. Tavakoli N, Yarmohamaddian, Mohammad H, Ajami S, Hassanzadeh A. Health management J 2006; 24, 17-22. 
9. Chamanreza et al., National plan of family physician and reference system quality 2011. PMID: 24167540

10. Hamidi H. Providing a multi-factor system in health electronic supply chain management, 2015.

11. Ali K, Shirkhani B, Akbar G, Abolghasem P. Field investigation of attractions and repulsions of family physician plan in view of senior students of Tabriz University of Medical Sciences and physicians of families working in Tabriz City healthcare networks, scientific $J$ Torbat Heidarieh Medical Sciences University. 2013; 1(1): 51-59.

12. Rabiei, R. The role of medical document and medical information in providing healthcare services and investigating current standards of medical information system, medical documents journal of Negah Noo, scientific committee of Mashhad medical Sciences University medical documents, $1^{\text {st }}$ year, special number of spring and summer 2001; 27-34.

13. Ramazanian $\mathrm{M}$, et al. Investigating the impact of information management capability on organizational performance, 2016.

14. Raeisi P et al. The impact of family physician plan on health indicators of mother and child in rural population, Medical Sciences and Healthcare Services University of Mashhad, 2009.

https://doi.org/10.1136/bmjopen-2018-021761

15. Ziaydloo D, Marzban S. Hospital information systems, 2008. www.himt.ir/thread3750.html

16. Sabahi S. Improvement of designation in family physician plan, 2015

17. Mehr S, Eika. Prioritizing applied domains of electronic health in Iran, based on factors effective on technology acceptance, M.A. thesis, Tarbiat Modares University, 2008. https://doi.org/10.5539/gjhs.v8n6p65

18. Hosseini AS, Seyed M. Comparing population information management relating to Iran health with national organization standard. Health Management J 2012; 50, 18-30. PMID: 23193499

19. Jalil A, Jahromi K, Mehdi H, Mohsen. Investigating Darab City rural people satisfaction rate from various dimensions of family physician perfromance, Fasa University of Medical Sciences. 2012; 2(3), 193-198.

20. Masoumeh A, Elaheh T, Khadivadi R, Sharifirad G. Awareness and attitude of Shahrekord City rural people towards family physician. Health Inform Manag J. 2010; 629-636.

https://doi.org/10.22034/APJCP.2016.17.11.4921

21. Farzandipour M, Zahra M, Hossein R, Sadegh, Jebeli M. Necessities of improving quality and safety of patient in hospital information system, health information system. 2014; 11(3), 293-307. https://doi.org/10.17485/ijst/2016/v9i26/92686

22. Farahmandian V. The role of information technology and communications in Iran health management with a glance at future, 2014. https://doi.org/10.6007/IJARCSEE/v1-i1/1161

23. Falahi A, Shahrbabaki N, Babak, Masoumeh H Investigating the satisfaction rate of referees with family physicians of Jiroft City healthcare centers and its relation with physician's demographic features, Zankoo medical Sci J, Kordestan University of Medical Sciences, summer 2015; 61-72. https://doi.org/10.5812/modernc.67215

24. Grayli B et al. Investigating views of health specialists about present and optima roles of general physicians in Iran health system, 2010

25. Mehrabi N. Promoting services to patients by military health electronic record. Paramedic faculty J Islamic Republic of Iran military 2007; 2(3): 28-30.

26. Bahadorimonfared A, Soori H, Mehrabi Y, Delpisheh A, Esmaili A, Salehi M, Bakhtiyari M. Trends of fatal road traffic injuries in Iran (2004-2011) 2013; (5): e65198 https://doi.org/10.1371/journal.pone.0065198

27. Borrell C, Plasencia A, Huisman M, Costa G, Kunst A, Andersen O, Bopp M, Borgan JK, Deboosere P, Glickman M, Gadeyne S, Minder C, Regidor E, Spadea $\mathrm{T}$, Valkonen T, Mackenbach JP. Education level inequalities and transportation injury mortality in the middle aged and elderly in European settings. Inj Prev 2005; 11(3): 138-142 https://doi.org/10.1136/ip.2004.006346

28. Chukuezi A, Nwosu J. Pattern of Deaths in the Adult accident and emergency department of a sub-Urban teaching hospital in Nigeria pattern of deaths in the adult accident and emergency department of a sub-Urban teaching hospital in Nigeria. Asian J Medical Sciences. 2010; 2(2): 66-69.

29. Copes WS, Champion HR, Sacco WJ, Lawnick MM, Gann DS, Gennarelli T, MacKenzie E, Schwaitzberg S. Progress in characterizing anatomic injury. J Trauma 1990; 30(10): 1200-1207.

https://doi.org/10.1097/00005373-199010000-00003

30. Etehad HS, Yousefzadeh-Chabok, A. DavoudiKiakalaye, A. Moghadam Dehnadi, H. Hemati and Z. Mohtasham-Amiri. Impact of road traffic accidents on the elderly. Arch Gerontol Geriatr 2015; 61(3): 489-493. https://doi.org/10.1016/j.archger.2015.08.008

31. Ghadipasha M, Vaghefi SS, Kazemi Esfeh S, Teimoori M, Ouhadi AR, Mirhosseini SM. An annual analysis of clinical diagnosis versus autopsy findings in fatal motor vehicle accident in legal medicine organization of Kerman province. Iran J Forensic Leg Med 2015; 34, 164-167. https://doi.org/10.1016/j.jflm.2015.05.013

32. EMS Medical Director Association of .California EMS Response Interavals. Position paper 1984; 54-57.

33. Gholipour C, Rad BS, Vahdati SS, Ghaffarzad A, Masoud A. Evaluation of preventable trauma death in emergency department of Imam Reza hospital. World J Emerg Med 2016; 7(2): 135-137. https://doi.org/10.5847/wjem.j.1920-8642.2016.02.009

34. Gill M, Goldacre MJ. Seasonal variation in hospital admission for road traffic injuries in England: analysis of hospital statistics. In J Prev 2009; 15(6): 374-378. https://doi.org/10.1136/ip.2009.021675

35. Haghparast B, Bogg HL, Hasselberg M. Pre-hospital trauma care resources for road traffic injuries ina middleincome country--a province based study on need and access in Iran. Injury 2011; 2(9): 879-884. https://doi.org/10.1016/j.injury.2010.04.024

36. Heydari ST, Hoseinzadeh A, Sarikhani Y, Hedjazi A, Zarenezhad M, Moafian G, Aghabeigi MR, Mahmoodi M, Ghaffarpasand F, Riasati A, Peymani P, Ahmadi SM, Lankarani KB. Time analysis of fatal traffic accidents in Fars Province of Iran. Chin J Traumatol 2013; 16(2): 8488.https://doi.org/10.3760/cma.j.issn.1008 1275.2013.02.003

37. Mehmandar M, Soori H, Mehrabi Y. Predicting and analyzing the trend of traffic accidents deathsin Iran in 2014 and 2015. Int J Crit Illn Inj Sci 2016; 6(2): 74-78. https://doi.org/10.4103/2229-5151.183017

38. Sadri G. A Model of Bus Drivers' Diseases: Risk Factors and Bus Accidents. Iranian J Med Sci 2015; 27(1): 39-41. https://doi.org/10.1016/j.aap.2015.09.025

39. Sami A, Moafian G, Najafi A, Aghabeigi MR, Yamini N, Heydari ST, Lankarani KB. Educational level and age as contributing factors to road traffic accidents. Chin J Traumatol. 2013; 16(5): 281-285. https://doi.org/10.3760/cma.j.issn.10081275.2013.05.005

40. Söderlund N, Zwi AB. Traffic-related mortality in industrialized and less developed countries. Bulletin of the World Health Organization 1995; 73(2): 175. PMID: 7743588 